Pobrane z czasopisma Annales I - Philosophy and Sociology http://philosophia.annales.umcs.pl Data: 26/04/2023 16:59:48

DOI: $10.17951 / i .2018 .43 .2 .9-25$

A N N A L E S

UNIVERSITATIS MARIAE CURIE-SKŁODOWSKA

LUBLIN - POLONIA

VOL. XLIII, 2

SECTIO I

2018

\author{
KATRINE HELENE ANDERSEN \\ ORCID: 0000-0002-6481-2804 \\ Universidad de Copenhague
}

\title{
Juan Larrea y el Nuevo Mundo: entre la filosofía y la mística
}

Juan Larrea i Nowy Świat: między filozofią a mistycyzmem

El filósofo Juan Larrea es principalmente conocido como poeta, aunque su obra durante décadas estuvo sumergida en el anonimato. Su producción poética se desarrolla principalmente en los años 20 durante su estancia en París, cuando escribe gran parte de sus poemas en francés. Generalmente, se le considera miembro de la generación del 27, así como padre del surrealismo español, aunque no rija consenso acerca de ninguna de las dos clasificaciones. Larrea era inconforme tanto en su estilo poético tanto como en su modo de pensar. El mismo autor explica en una carta a Vittorio Bodini en 1964 que:

Los otros poetas $[\ldots]$ operaban en el campo de la literatura dentro de la sociedad vigente de alcances, a mi juicio, provinciales. En el fondo yo era un místico de la poesía arrastrado por apetencias de otro género harto más desorbitado [...] Mi problema era esencial y universal, de vivencia profunda, de locura si se quiere: en puridad, religioso ${ }^{1}$.

Aquí hallamos una clave en el pensamiento filosófico de Larrea: mezcla la filosofía con la poesía, la religión, e incluso la psicología, sin percatarse de ello. No se inscribe en ninguna escuela o tradición filosófica ni le causa remordimiento metodológico mezclar disciplinas de carácter tan diverso. Lo que motiva su pensamiento, al menos en esta primera etapa de su actividad literaria y filosófica, es alcanzar el más allá y la idea de lo universal. Curiosamente las ideas de lo universal y el más allá se convierten en un proyecto personal; tanto Orbe como Diario del Nuevo Mundo son testimonios de un itinerario personal que lo lleva al más allá.

En lo que sigue, voy a analizar los pasos que emprende Larrea en su afán por transcender este mundo y tener acceso al más allá tal y como se articulan en

1 G. Morelli, Introducción, [en:] J. Larrea, Poesíay Revelación, Madrid 2009, pp. XXIII-XXIV. 
Pobrane z czasopisma Annales I - Philosophy and Sociology http://philosophia.annales.umcs.pl Data: 26/04/2023 16:59:48

sus diarios Orbe y Diario del Nuevo Mundo. El suyo es un proyecto personal al tiempo que filosófico, y como tal universal, precisamente porque Larrea busca saltar de lo individual a lo universal. El encuentro con América Latina marca considerablemente al autor, quien deja testimonio en Orbe del efecto que tuvo sobre él su estancia en Perú y en Diario del Nuevo Mundo de su vida en México. Voy a analizar sus vivencias en "el nuevo mundo" con el fin de determinar si son experiencias místicas, tomadas en el sentido más amplio de la palabra, y averiguar en qué sentido contribuyen a su intento de transcender el mundo físico. Las ideas de William James acerca de las experiencias religiosas, en especial su indagación en la mística, sirven como punto de partida para tratar de determinar si las de Larrea son experiencias místicas y qué valor tienen para su proyecto filosófico. Analizaré la relación entre las vivencias de Larrea y los lugares donde las experimenta, es decir Perú y México. Larrea mismo se denomina "un místico de la poesía", pero qué le aporta la "mística" y en qué medida se convierte la mística en un vehículo de conocimiento son algunas de las preguntas que pretendo contestar.

La poesía de Larrea presenta un claro anhelo por el más allá. El autor no define detalladamente en qué consiste su idea del más allá, pero intuimos que es un ser transcendental al que podemos acceder si logramos traspasar el mundo físico como, por ejemplo, en el poema "Evasión" donde la tierra y el mundo físico aparecen claramente como elementos que imposibilitan el transcender este mundo: "Finis terre la / soledad del abismo / Aún más allá / Aún tengo que huir de mí mismo". El Yo o el "mí mismo" aparecen en este contexto como una delimitación que impide entrar en contacto con el más allá, un problema que es central en toda la obra de Larrea. Aunque tras un viaje a Perú en 1930-31 abandona la poesía como género literario y empieza a escribir ensayos, el más allá sigue siendo su gran preocupación, tanto filosófica como personal.

\section{FIN DE LA POESÍA}

Entre 1926 y 1932 Larrea escribe el diario que los críticos denominan "diario poético, espiritual e intelectual”" Se tituló provisionalmente Universo Poético, pero se publica con el título Orbe. Larrea pretende publicarlo en España en 1936, pero su intención se ve frustrada por el comienzo de la Guerra Civil española, al

2 J. Larrea, Versión Celeste, Madrid 2003, p. 67.

3 H. López González de Orduña, Hacia una definición de Orbe de Juan Larrea, "Bulletin of Hispanic Studies" 2001, Vol. 78(3), DOI: https://doi.org/10.1080/000749001300342070, pp. 361370; M. Nieto Nuño, Introducción, [en:] J. Larrea, Versión Celeste, Madrid 2003, pp. 9-54. 
Pobrane z czasopisma Annales I - Philosophy and Sociology http://philosophia.annales.umcs.pl Data: 26/04/2023 16:59:48

Juan Larrea y el Nuevo Mundo: entre la filosofía y la mística

igual que el poemario Versión Celeste. En 1990 se publica, por fin, Orbe aunque en una versión reducida. Elide Pittarello considera que:

Para el autor era genéricamente un libro de notas, donde se yuxtaponen muestras de diferentes formaciones discursivas, como por ejemplo la confesión personal y el análisis sociológico, el manifiesto poético y la predicción religiosa, la anécdota doméstica y la política planetaria ${ }^{4}$.

Es una clara muestra de la situación en la que se encontraba Larrea personalmente, pero también es un anticipo de la trayectoria posterior y especialmente de lo que le ocurre tras la llegada a México como exiliado en 1939. Orbe está teñido de una crisis existencial personal interior que busca consuelo a través de la escritura. Helene López González de Orduña resalta que en Orbe Larrea utiliza la escritura como terapia para superar su crisis personal ${ }^{5}$, mientras que Juan Manuel Díaz de Guereñu considera que Larrea en esos años evoluciona desde el autor de los versos vanguardistas al profeta que "predicó un paraíso improbable". Es decir, que Orbe presenta el testimonio de un autor en tránsito entre dos hombres: el autor de versos en crisis y el ensayista resuelto a definir una nueva realidad.

Entre otras cosas, Orbe presenta las reflexiones y experiencias vividas durante un viaje a Perú en 1930-31. El país andino tiene gran impacto sobre Larrea, pero la escritura viene a ser una manera de poner orden y "aguzar mi imaginación hacia una razón, hacia un punto de apoyo, hacia una claridad momentánea"7 proclama Larrea, de modo que Orbe es un testimonio de las experiencias espirituales y psicológicas vividas y, además, un ejercicio intelectual que conceptualiza las experiencias personales del autor. Por la misma razón, el libro contiene una larga serie de contradicciones e incongruencias filosóficas y no ha de tomarse como un texto filosófico en toda regla, sino como una serie de reflexiones y sensaciones de un filósofo en ciernes.

Este bilbaíno que había vivido fuera de su tierra natal en varias ocasiones, tanto en Madrid como en París, conecta con América Latina de una manera profunda que le transforma personalmente y le hace cambiar su procedimiento para transcender el mundo físico. Anteriormente la poesía le había servido en su búsqueda de una vía de acceso al más allá, pero de repente se da cuenta de que la poesía había sido un mero consuelo que, en vez de acercarle al más allá, había supuesto una pobre sustitución de aquello que buscaba. Declara el fin de su poesía, estando el autor en Perú. Escribe:

4 E. Pittarello, Juan Larrea: Desfiguraciones al uso, "Etudes Hispaniques" 1992, núm. 19, pp. 343-354.

5 H. López González de Orduña, op. cit., p. 362.

6 J.M. Díaz de Guereñu, Orbe de Juan Larrea, "Ínsula" 1990, Vol. 527, pp. 7-8.

7 J. Larrea, Orbe, Barcelona 1990, p. 28. 


\section{FIN DE MI POESÍA}

Presumo que el fin de mi concepto de poesía es llegado. Que la poesía era para mí una válvula de escape, un medio consolador, una sublimación de lo que no encontraba en el mundo. Hoy he llegado a la identificación de la vida con la poesía. Todos los elementos constitutivos de la poesía, imaginación, sentimiento, armonía, proyectados a una irrealidad simbólica, es decir, ocultadora, tienen libre entrada en mi vida real, contrastados por el acontecimiento, por lo verdadero. Y veo cómo esta mi ciencia poética de la vida no está sino en sus comienzos, siendo sus promesas extraordinariamente fecundas. Hay libre campo para imaginar, sentir, amar con la más apasionada y profunda convicción. La realidad exterior e interior se funden, se completan, se intercambian, forman una única existencia ${ }^{8}$.

Larrea pretende hacer de su vida un proyecto poético con todo lo que aquello conlleva. No define claramente en qué consiste su nuevo proyecto, pero intuimos que ha pasado por un cambio radical, posiblemente una experiencia de carácter místico que le ha acercado a su objetivo y le aleja de la poseía como género. Abandona la poesía porque no le proporciona lo que busca sino, al contrario, sirve como una sustitución que le aleja de su objetivo. La poesía no le sirve para transcender este mundo, sino que lo ancla en el mundo social. Lo que desea es hacer posible la fusión entre su yo interior y la realidad exterior y extraterrenal y, para ello, la poesía resulta demasiado concreta. Larrea descubre que su existencia individual tiene relación con la existencia de algo universal, con una voluntad superior y objetiva. Es un descubrimiento en etapas provocado por el exterior con claras reminiscencias místicas.

\section{LA MÍSTICA Y LA FILOSOFÍA}

La mística es un campo lleno de paradojas y complejidades, especialmente si consideramos que es un campo que abarca tanto la religión como lo que podríamos llamar "la mística profana" o "la mística natural". A pesar de ser principalmente un fenómeno religioso y cristiano, encontramos también experiencias místicas en las tradiciones budista e hindú, e incluso en contextos no-religiosos. El estudio de la mística se basa fundamentalmente en testimonios personales, lo cual

\footnotetext{
8 Ibídem, pp. 29-30.

9 J. Martín Velasco, El fenómeno místico, Madrid 2009. Este estudio contiene un capítulo sobre las "Formas no religiosas de mística", en el que aparecen denominaciones como "mística natural", "misticismo naturalista" o "mística salvaje o silvestre". Todos designan: "[...] dilatación de conciencia, estados alterados de conciencia, conciencia cósmica, sentimiento oceánico, intuición del fundamento de lo real, etcétera". Martín Velasco discute las posibles interpretaciones de estas experiencias y en qué sentido se diferencian estas interpretaciones de las religiosas (ibídem, pp. 97-112). A nosotros nos sirve el marco conceptual que proporciona el estudio, el contenido del cual no defiere mucho del estudio de James.
} 
Pobrane z czasopisma Annales I - Philosophy and Sociology http://philosophia.annales.umcs.pl Data: 26/04/2023 16:59:48

complica, como veremos a continuación, una definición exacta de la experiencia. No obstante, todas las experiencias descritas tienen en común algunos aspectos que hacen posible caracterizarlas de manera más o menos uniforme y, como resultado, usarlos en el campo de la filosofía.

William James analiza en su The Varities of Religious Experience de 1902 la experiencia religiosa. En las veinte conferencias que incluye el libro la analiza como fenómeno religioso a la vez que psicológico, y examina el valor que tiene para la filosofía. Dirigiéndose, como hace James, a filósofos, la verdad tiene que ocupar un lugar fundamental en su estudio. Son muchos los teóricos que han señalado las incongruencias en su argumentación al respecto, pues James valida las experiencias religiosas, pero no queda claro si su valor reside en su función o en la naturaleza de las mismas ${ }^{10}$. Su estudio apunta a la relación entre nosotros y un ser infinito, pero no pretende usar las experiencias religiosas como prueba ni definición de la creencia en lo infinito. Por el contrario, propone James, revelan que podemos lograr la unión con algo más grande que nosotros mismos y que, en esa unión, encontramos nuestra mayor paz ${ }^{11}$. James alega que el valor de las experiencias radica en su valor para la persona individual, mientras que la ciencia se aleja de lo personal y pretende construir una verdad basada en criterios objetivos. Dice que la religión es un capítulo monumental en la historia del egoísmo humano y que en muchos sentidos el darwinismo ha ganado al conocimiento religioso. Como resultado, la ciencia se ha desvinculado de todo tipo de consciencia personal y de la simpatía ${ }^{12}$. El modo de pensar de Larrea es inmensamente personal, especialmente en esta primera etapa, tanto que para una mente académica resulta desafiante seguir su razonamiento y argumentación. José Luis Abellán ha calificado la filosofía de Larrea de "pensamiento delirante"13 y el mismo Larrea, en una carta a Abellán, si no le da la razón, manifiesta que el suyo es un pensamiento de índole poético-cultural que se diferencia de la lógica académica ${ }^{14}$. Asegura que

10 Michael Hodges y Richard Rorty analizan la argumentación de James. Rorty, por su lado, comenta que James no se decide entre pensar que el supernaturalismo es la verdad porque es bueno para nosotros o porque efectivamente existe mucha evidencia experimental que lo convalida, mientras que Hodges señala que James comete un error argumentativo al insertar la experiencia mística en la misma línea que las experiencias demenciales, lo cual infiere, opina Hodges, una reconsideración del fenómeno. Véase R. Rorty, Some Inconsistencies in James's Varieties, [en:] William James and a Science of Religions, New York 2004, pp. 86-97; M. Hodges, The Claims for Mysticism in the Varieties of Religious Experience, "Journal of Speculative Philosophy" 2011, Vol. 25(4), DOI: https://doi.org/10.5325/jspecphil.25.4.0396, pp. 396-411.

11 W. James, The Varieties of Religious Experience, New York 2015, p. 751.

12 Ibídem, pp. 698-700.

13 J.L. Abellán, El exilio filosófico en América. Los transterrados de 1939, Madrid 1998, p. 285.

14 Ibídem, pp. 317-319. 
Pobrane z czasopisma Annales I - Philosophy and Sociology http://philosophia.annales.umcs.pl Data: 26/04/2023 16:59:48

sus convicciones son producto no de una conciencia racional, sino de una "revelación". Es decir que, a pesar de las claras pretensiones y objetivos filosóficos de Larrea, su modo de acercarse a la filosofía difiere, como ya mencionado, de la tradición filosófica europea corriente. Ni las experiencias místicas ni las revelaciones son ajenas a su proyecto filosófico. Al contrario, la mística parece empujarle hacia la filosofía que va a desarrollar posteriormente.

El capítulo sobre "Mysticism" de James es de especial relevancia para el estudio de las experiencias de Larrea. La aproximación de James a la mística incluye las experiencias místicas, por muy personales que sean, en el campo de la filosofía, y las inserta en un marco conceptual útil para un análisis de la evolución de Larrea durante sus etapas en Perú y México y de los pasos desde la poesía hasta la filosofía. James incluye en su estudio tanto las experiencias estrictamente religiosas como las místicas de carácter profano. Estudia los testimonios de personas que informan haber vivido una experiencia mística y añade que posiblemente en todas ellas han estado presentes algunas condiciones patológicas, pero ello no dice nada sobre el valor del conocimiento de consciencia que han inducido ${ }^{15}$. James enlista cuatro criterios para una experiencia mística: Inefabilidad, cualidad noética, transitoriedad y pasividad. Los dos últimos determinan que un estado místico nunca permanece durante mucho tiempo, pues son pocos los ejemplos en los que se sustentan más de media hora o, como mucho, una hora o dos. Después se desvanecen y la persona que los ha vivido solo tiene un vago recuerdo de la experiencia. No obstante, el sujeto de la experiencia suele tener una profunda sensación de la importancia de lo vivido. Además, la experiencia mística suele ser pasiva, en el sentido que son pocos los que pueden evocarla, mientras que en la mayoría de los casos el sujeto suele tener la sensación de pasar a un estado de consciencia en el que la voluntad individual obedece a una fuerza superior que utiliza al individuo como medio para la escritura o para algún tipo de discurso profético, y que a veces provoca un trance. En muchos casos no tiene ningún impacto directo sobre la vida individual del sujeto, aunque un recuerdo de lo vivido siempre permanece. Las experiencias son inefables y no pueden ser compartidas o transferidas a otros. No obstante, tienen una cualidad noética para la persona que las ha vivido. Para el sujeto tienen un valor cognitivo indudable y se consideran acceso a una verdad no alcanzable para la mente intelectual. Son revelaciones o iluminaciones llenas de importancia y significado y, por eso, poseen un alto grado de autoridad ${ }^{16}$. A primera vista la inefabilidad aparta la experiencia de la filosofía porque ¿cómo puede una experiencia destinada a ser personal, sin posibilidad de ser compartida

15 W. James, op. cit., pp. 573-574.

16 Ibídem, pp. 538-540. 
Pobrane z czasopisma Annales I - Philosophy and Sociology http://philosophia.annales.umcs.pl Data: 26/04/2023 16:59:48

por otros, tener valor filosófico? Pero la concordancia acerca de la naturaleza de estas experiencias hace, al menos a James, aceptar su validez, también para la filosofía. En todo caso, las experiencias tienen una autoridad aplastante sobre el individuo y nunca dejan al sujeto de la experiencia indiferente, sino, más bien cambiado. Independientemente de si se trata de un estado mental místico inducido por el alcohol o la intoxicación, o si es una experiencia mística religiosa, provocan conocimiento acerca de algo que tiene relevancia metafísica. Martín Velasco, de la mano de Michel Hulin, define las experiencias místicas profanas en términos parecidos a los de James y sugiere que tienen en común su carácter de "revelación aplastante de una realidad frente a la cual el mundo sensible y la existencia social no son más que un teatro de sombras" ${ }^{17}$. La experiencia en sí puede resultar violenta, ya que el sujeto es catapultado a un universo cualitativamente diferente del de la vida ordinaria, lo que aporta un conocimiento y contacto con algo elevado con la consiguiente dificultad de readaptación al volver a la normalidad. Es decir, todas las experiencias místicas dejan una clara impronta en el sujeto, lo cambian y lo dejan convencido de estar más próximo a una realidad metafísica.

James apunta que la verdad mística solamente existe para el individuo que la experimenta ${ }^{18}$, en ese sentido el conocimiento que aporta es claramente más intuitivo que conceptual, por lo que el científico lo despacha como irrelevante. El discurso acerca de la mística también es claramente intuitivo y personal, pero, no obstante, es lo suficientemente objetivo como para ser reconocido por los demás que han vivido una experiencia similar. Existe, por lo tanto, un criterio de intersubjetividad. En este contexto la intersubjetividad simplemente establece la presunción de lo ocurrido, opina James, mientras que en otros contextos es un criterio de objetividad, como señala Michael Hodges ${ }^{19}$. Al parecer a James no le interesa definir un criterio de verdad de las experiencias, pero se queda en la relevancia que tienen para los que las vive y en el hecho de que las vive más de una persona.

En el caso de Larrea, el carácter personal de las experiencias no las hace menos relevantes para su proyecto filosófico, al contrario. Él anhela claramente el contacto con una realidad metafísica, primero en su poesía y posteriormente en sus ensayos y diarios, y para ello se dirige primero a su yo individual como fundamento, y después al ser superior. Antes de anunciar el fin de su poesía hace mención de la mística en una entrada en Orbe. Sin haber tenido todavía la primera experiencia personal de rasgos místicos escribe que: "Pensar en Dios, como hacen los místicos, es una manera de pensar en sí mismo sin los peligros de pensar en sí

17 J. Martín Velasco, op. cit., p. 102.

18 W. James, op. cit., p. 565.

19 M. Hodges, op. cit., p. 404. 
mismo"20. La mística aquí está lejos de proporcionarle el fundamento que necesita para transcender este mundo, pero es consciente de sus posibilidades y poco tiempo después deja testimonio de la primera experiencia.

\section{ESTANCIA EN PERÚ}

Primero en Perú y más tarde en México, Larrea vive una serie de experiencias que afectan su estado personal de una manera radical y como resultado cambia su estructura psicológica. Algo ocurre en Perú que le hace abandonar la poesía como género y empezar otro proyecto intelectual. El entorno, su contexto geográfico, produce un cambio en su interior y le revela una dualidad en su ser. Ocurre entre Arequipa y Cuzco y tiene carácter de una crisis interior psicológica y, a la vez, de una experiencia religiosa o mística que le revela la existencia de "algo más", un ser "extraterreno". El autor mismo describe la experiencia así:

\section{CUZCO}

En la altura he notado primeramente una descoyuntación del yo, como si estuviese compuesto de más de un elemento, cosa que se me produjo con grandes luchas y violencias en Arequipa.

De esta nueva descoyuntación resultó un nuevo estado psíquico en el que una especie de potencia absoluta reinaba sobre el cuadro interior de complejos. Una potencia desinteresada de todo lo que fuera relativo de modo que la introspección daba un raro espectáculo. No se sabía dónde estaba el yo, si en esa potencia que en cierto modo me era extraña, o en el resto, en el lastre subconsciente con todo su acarreo de vida pasada, que por su estado de angustia no podía ofrecerme un apetecible abrigo.

[...] era como un preliminar de la pérdida de todas las potencias interiores; la memoria se oscurecía, la voluntad era palo de ciego, el sentido del tiempo y del espacio desaparecía totalmente, hasta el punto de que por violentos que fueran los esfuerzos no se podía salir de una sensación de extraterrenidad ${ }^{21}$.

Larrea experimenta un cambio en su interior provocado por el exterior, en este caso es la altura, pero posteriormente todo tipo de cambio físico, por ejemplo, enfermedades físicas o el traslado definitivo a México en 1939, le provoca un cambio psicológico. A primera vista, la experiencia que describe concierne claramente a su yo personal, pero también le provoca la sensación de algo transcendental. "Una potencia absoluta" reina sobre él, pero no tiene palabras para definir esa potencia que le deja con una sensación de "extraterrenidad". La experiencia se divide en dos: aquello que concierne a su yo y aquello que tiene que ver con "la potencia absoluta". La totalidad de la experiencia es inefable y meramente puede aproximarse a una descripción conceptual. Claramente el aspecto psicológico

20 J. Larrea, Orbe, p. 16.

${ }^{21}$ Ibidem, p. 17. 
Pobrane z czasopisma Annales I - Philosophy and Sociology http://philosophia.annales.umcs.pl Data: 26/04/2023 16:59:48

resulta más fácil de describir; en cambio, "la potencia absoluta" y la "extraterrenidad" se escapan del vocabulario convencional. La experiencia de Larrea es transitoria, le sobresalta, es decir, es pasivo ante ella. Es inefable en su totalidad, aunque él busca un marco conceptual en el que insertar lo experimentado. La cualidad noética es indudable, no duda de su verdad ni de su autoridad. En estos sentidos la experiencia descrita por Larrea tiene claros rasgos místicos, especialmente si aceptamos los criterios enlistados por James y por Velasco, aunque todavía es una experiencia incompleta, ya que Larrea en esta ocasión no vive la unidad absoluta con un ser u orden superior. Posteriormente, ya estando en México, la presencia de un ser transcendental se consolida. No define en qué consiste este ser superior y el vocabulario que aplica al denominarlo varía desde Voluntad objetiva hasta Ser-Espíritu pasando por Conciencia objetiva y Voluntad de conciencia. En ocasiones, subraya la relación de lo experimentado con la geografía y llega a denominarlo Amor de América ${ }^{22}$, pero en Orbe las experiencias todavía se presentan como un sobresalto de sensaciones a las que está tratando de sacar sentido, y el sentido, en un primer momento, está en lo puramente psicológico. Son los efectos sobre el yo los que captan su mayor interés y preocupación. Las experiencias místicas de Larrea en Perú no le aportan en este momento un conocimiento religioso o una unión con un ser superior, sino que ponen de relieve la insuficiencia del yo individual y de la vida vivida en términos concretos. Orbe presenta las experiencias y las reflexiones de un autor en crisis porque está en tránsito entre lo que era y lo que viene a ser, y entre su concepto de una realidad en la que la poesía le servía como válvula de escape y la nueva realidad en la que va a hacer de su vida un proyecto poético. El abandono del yo individual definitivo viene después.

James caracteriza la experiencia mística como, principalmente, panteísta, optimista y antinaturalista, aunque, admite que los grandes místicos españoles no eran panteístas. Larrea tampoco lo es pero el optimismo rige, en gran parte, sus experiencias místicas. En algunas entradas de Orbe, el optimismo se presenta relacionado con la satisfacción que le aporta el aprehender la insuficiencia y relatividad de yo, y comprender que este obedece a una universalidad. Lo describe como un renacimiento en un estado purificado:

Sin duda el yo, esa unidad que dentro del individuo preside a su eficaz existencia, ha estado muerto. De ahí esa clara sensación de resurrección que ahora experimento, y con las primeras sensaciones sensuales de alegría, el gozo de volver a una perdida vida.

Y todo en mi interior ha sido barrido, purificado. De estos últimos años de vida no queda sino el recuerdo voluntario [...] Mi carne y mi espíritu vuelven a ser regidos por la salud universal y a bañarse en el relativo del mundo.

${ }^{22}$ Idem, Diario del Nuevo Mundo, Madrid 2015, pp. 82, 84-86, 101. 
Porque como antes he notado, sólo una sensación de absoluto primaba en mi cerebro; es decir que había una pérdida de gusto de los valores relativos y de ahí esa sensación de absoluto en un todo parecida a la del vacío ${ }^{23}$.

Si antes había notado la presencia de una potencia absoluta, ahora da el paso siguiente hacia la unión de la que hablaba James. Aprehende que el yo obedece a un ser superior, "una salud universal", porque su mera existencia relativa está al mando de un ser absoluto.

A continuación de la cita anterior, llega a negar la existencia de lo absoluto: "El absoluto no existe y si existiera no se podría sentir"24; no nos queda más remedio que comprender que el absoluto no existe sino que es porque la existencia de las cosas está vinculada a la experiencia sensorial, y un ser de las dimensiones de lo absoluto no se deja sentir sensorialmente. Para percibir seres de tal naturaleza hay que estar en condiciones determinadas, las cuales Larrea define como supersalud. La supersalud es una "salud completa dentro del individuo" que, paradójicamente, está relacionada con la enfermedad porque esta requiere una recuperación y una salvación. Larrea se resiste a sentir lo absoluto, aunque las condiciones para ello van cobrando forma. Posteriormente, se completa su unión con el absoluto, y la relación entre lo físico, lo mental y lo geográfico que establece aquí se vuelve a manifestar. En el Diario del Nuevo Mundo atestigua que en Lima tuvo "por primera vez conciencia de la relación íntima entre enfermedad física y salud mental" 25 , y esta idea promueve en él el afán por buscar las conexiones entre psiquismo y fisiología. Apunta Larrea:

Todas mis enfermedades se han hallado como subordinadas a la conciencia, hasta el punto de que llegado el momento en que salta la chispa de la comprensión la enfermedad cede si no desaparece. [...] el proceso de mi gran enfermedad de antaño hasta la operación, y el de su larga convalecencia y reabsorción morbosa, han estado en franca y directa relación con las vicisitudes de mi adquisición de conciencia $[\ldots]^{26}$.

Durante su viaje a Perú lo operan de una úlcera duodenal y después comprende que la enfermedad física obedece a una conciencia superior y colectiva caracterizada por ser optimista. Abre paso a avances en otros campos, de modo que al sufrir un trastorno importante es preciso salir en busca de su sentido, abrir los ojos, disponerse a comprender. Es decir, que para Larrea las enfermedades abren paso, a pesar de su carácter fisiológico, a un mayor nivel de comprensión metafísica

${ }^{23}$ Idem, Orbe, pp. 17-18.

${ }^{24}$ Ibídem, p. 18.

25 Idem, Diario del Nuevo Mundo, p. 110.

26 Ibidem. 
Pobrane z czasopisma Annales I - Philosophy and Sociology http://philosophia.annales.umcs.pl Data: 26/04/2023 16:59:48

y da acceso a una realidad superior. Ocurre cuando se enferma su mujer y cuando su hijo está a punto de morir a causa de una encefalitis. Un añadido de la máxima importancia a la recuperación de estas enfermedades es "la mentalidad nueva. [El] $[\mathrm{h}]$ ombre nuevo"27 que salen de estas situaciones. En el Diario alude en varias ocasiones a las experiencias vividas en Perú; durante su convalecencia "nació la conciencia optimista en reacción contra la insuficiente situación individual, afirmándose así sobre los valores particulares los propios de la generalidad"28.

Estamos ante una situación en la que, por un lado, las experiencias místicas provocadas por el contexto, especialmente la altura en Cuzco, y, por otro lado, algo tan tangible como la enfermedad física provocan cambios en el interior del autor. Si aceptamos, como propone Velasco, que el núcleo central de la experiencia mística profana consiste en una nueva forma de conciencia que supera el conocimiento objetivo y que cae fuera de los conceptos y determinaciones convencionales, pero se basa en el contacto intuitivo e inmediato con su objeto ${ }^{29}$, las experiencias de Larrea son claramente místicas. Además, añade Velasco, un criterio para la experiencia es superar la división originaria de lo vivido en "bueno" y "malo" para que la plenitud que yace en nosotros aflore a la conciencia ${ }^{30}$. Larrea reconoce la división de lo vivido en positivo y negativo y arguye que ambos son necesarios porque se complementan y se subrayan, pero en el momento no podemos juzgar la situación. De lo malo puede venir lo bueno. Estando en Cuzco lo describe:

\section{CUZCO}

El bienestar que experimento ahora corresponde exactamente al antiguo malestar, es decir que son entre sí como el positivo y el negativo de una fotografía. Independiente de ellos es el yo superior, la inteligente capacidad que para conocer la realidad utiliza otros elementos que el color del momento presente ${ }^{31}$.

Rige un orden superior que controla el equilibrio entre "bueno" y "malo", de modo que los polos se complementan y tejen la totalidad de la realidad. Tanto como una superación de la división en bueno o malo no se ve aquí, pero Larrea entiende que él como yo individual no posee el criterio necesario para hacer la distinción.

Particularmente la altura de Cuzco provoca en Larrea un cambio. La altura le acerca física y cognitivamente a la aprehensión de una realidad metafísica y transcendental. Destruye el cerebro, dice, porque el cerebro es físico:

27 Ibidem, p. 51.

28 Ibidem, pp. 89-90.

29 J. Martín Velasco, op. cit., p. 104.

30 Ibídem, p. 102.

31 J. Larrea, Orbe, p. 19. 
Pobrane z czasopisma Annales I - Philosophy and Sociology http://philosophia.annales.umcs.pl Data: 26/04/2023 16:59:48

[...] la altura manifiesta su influjo destructor en el cerebro. Aleja al hombre de todas las tentaciones inmediatas para lanzarlo al vacío, indiferente por las cosas de este mundo (tiempo y espacio) haciéndole en cambio navegar por los mares religioso-imaginativos ${ }^{32}$.

Como ya hemos visto anteriormente, su mayor preocupación en Orbe es la progresiva pérdida del yo individual. Las experiencias en Perú tienen rasgos místicos evidentes y cumplen con los criterios de James, pero no llega a producirse la plena satisfacción de una unión con una realidad superior. Al contrario, en esta fase, las experiencias todavía le causan frustración porque descubre que el yo individual es insuficiente e incluso llega a afirmar que no existe ${ }^{33}$. La plenitud y el optimismo purificado se presenta años después cuando comienza su nueva vida en México.

\section{EXILIO EN MÉXICO}

En 1939 Larrea se exilia definitivamente en América Latina, al igual que muchos intelectuales españoles de la época. Comienza su nueva vida fuera de España en México y, tras estancias en EE.UU., vive sus últimos días en Argentina. Durante los primeros años en México escribe el Diario del Nuevo Mundo. El diario comienza en abril de 1940 y concluye en agosto de 1947. Aunque no sean constantes, las entradas —en 1946 no se produce o no se conserva ninguna - abarcan un período crucial en su pensamiento, así como en su vida personal. En estos años se acuñan las ideas centrales de su prosa y la poesía empieza a ocupar una posición más teórica y abstracta tras el abandono del verso. El tema central de las anotaciones que constituyen el Diario es la Voluntad objetiva o la Conciencia objetiva (que habitualmente escribe con mayúscula), es decir, lo transcendente y colectivo. Al igual que en el caso de Orbe, no se trata de un diario íntimo que describe las reacciones personales a lo vivido sino de una bitácora de ideas y experiencias al parecer aleatorias pero que bajo mayor inspección revelan las mismas inquietudes que había expresado en su poesía y, en cierta medida, en Orbe: la búsqueda de una vía de acceso al más allá. Se trata de una serie de comentarios y reflexiones personales, muchas veces inconexas, que, no obstante, no permite pintar un retrato íntimo del autor, puesto que Larrea proyecta lo íntimo hacia el exterior para así centrarse en la búsqueda del más allá. A diferencia de Orbe, el Diario del Nuevo Mundo presenta a un Larrea más sereno, que deja testimonio de los acontecimientos exteriores y las reflexiones personales. La crisis ya no es interior, sino exterior, y el autor está más centrado en la búsqueda de una fórmula generalizada

32 Ibidem, p. 20.

33 Ibidem, p. 21. 
Pobrane z czasopisma Annales I - Philosophy and Sociology http://philosophia.annales.umcs.pl Data: 26/04/2023 16:59:48

que le permita transcender este mundo. El Diario comienza con una clara intención de pasar página tanto en lo personal como en lo general: "[d]esde anoche estoy cambiado interiormente", pero también "[1]a tragedia española ha vencido su fase aguda. Lugar existe, pues, para que en el nuevo clima otros brotes se abran paso"34; el Nuevo Mundo constituye el escenario idóneo para el cambio y el florecimiento de la voluntad suprema. La ruptura con la vida anterior no es solo un cambio geográfico y de género literario, sino que supone la culminación definitiva de la historia anterior y connota universalidad: "América [...] La universalidad se concibe aquí, se acrisola aquí. Todo concurre, material y espiritualmente" ${ }^{35}$.

En Diario del Nuevo Mundo, Larrea da el salto definitivo hacia la unión con un ser superior del que hablaba James. El texto mismo no contiene descripciones de experiencias místicas, pero muchas entradas atestiguan haber vivido un cambio que lo ha llevado a una comprensión y relación con una realidad metafísica, aunque las experiencias no tengan el carácter inefable que vimos en Orbe. El autor mismo se percata de que es la misma angustia que lo llevó a escribir el diario anterior la que ahora lo emplaza a escribir el nuevo diario; si la obra de entonces estaba llamada a revolucionar "las ideas acerca del pensamiento y la vida subjetiva", la nueva está destinada a revolucionar las nociones generales de la acción, y subraya que: "Descubierto esto, adquirida conciencia, puede, como en el tratamiento psicoanalítico, ir cediendo la angustia hasta convertirse en el sentimiento contrario, en entusiasmo" ${ }^{\prime 36}$. Él mismo alude, en relación a sus experiencias, a la psicoanalítica, y en más que una ocasión menciona a Sigmund Freud. Oscila entre una explicación psicológica y espiritual de lo vivido porque, mientras no hay lugar a duda acerca de la espiritualidad de su conocimiento adquirido, el mismo autor no encuentra este tipo de comprensión incompatible con la psicología y con una explicación fundada en un criterio objetivo.

En Orbe, las experiencias místicas eran incompletas en el sentido que no presentaban una solución o revelación de aquello que buscaba, meramente le dejaban en una situación de angustia al descubrir su existencia social e individual frente a lo que denominaba "potencia absoluta" o "extraterrenidad". En cambio, el Diario revela un pensador en el que se ha consumado la experiencia mística y ha unido su yo a un ser superior. Además, vuelve a un estilo claramente poético sin recuperar el verso anterior. El 13 de noviembre de 1943 escribe:

Despertar.

Abrir los ojos a esa voluntad que no es $m i$ voluntad, sino la voluntad universal.

${ }^{34}$ Idem, Diario del Nuevo Mundo, p. 35.

35 Ibídem, p. 47.

36 Ibídem, p. 136. 
Conciencia.

Voluntad dinámica, distante del estatismo del sueño.

Todos los aparentes tirones hacia abajo, hacia el temor y la inconsciencia, de estos últimos tiempos son en realidad parte del mecanismo que lleva al ente consciente a asomarse a las ventanas del exterior. Son como los tirones hacia abajo ejercidos en una cuerda que, formando parte de una polea, son necesarios para la elevación del objeto atado al otro extremo. Así estos tirones del intestino.

Abrir los ojos a esa voluntad significa tener la mira puesta en el destino de América, en su amor y en la imaginación creadora que le presta una dimensión propia, universal, un orden nuevo. Es integrarse en el dinamismo absoluto, tanto como en el objetivo en el subjetivo.

Todo es, una vez más, para lo mejor.

Optimismo $^{37}$.

Se ha efectuado la fusión o unión con un ser superior. Ya no es relevante hablar de una voluntad individual, pues el fenómeno individual se encuentra adscrito a una voluntad universal. La entrada no es el testimonio directo de una experiencia mística, sino la reflexión conceptual de una experiencia o un evento que le ha hecho ver y comprender el mundo en términos parecidos a los de los místicos. Él, como ser individual, actúa dentro de un orden superior que es el impuesto por el "Nuevo Mundo". Siente la plena satisfacción y la paz de la que hablaba James, la que solo se podía alcanzar gracias a una comprensión religiosa del mundo, y acepta su nueva posición con gratitud y optimismo.

No define concretamente en qué consiste la voluntad universal, pero es una voluntad positiva llena de amor. Resume su unión con el ser superior de esta manera:

Existe un pensamiento objetivo, una voluntad objetiva a la cual se encuentra mi fenómeno individual adscrito. Ambos han trabajado a través de mi subjetividad en acorde con los sucesos exteriores. Este es el orden que empezó a revelarse en la sierra peruana con motivo de las antigüedades y el que después no ha dejado de actuar. A él hay que atribuir mi libro, mi enfermedad y los sucesos posteriores $[\ldots]$.

Ahora bien, esta voluntad objetiva no puede ser sino la voluntad del Nuevo Mundo, dinámica y sobre todo optimista. Va hacia lo mejor. Es la misma voluntad positivamente universal que produjo el cristianismo y que después la produjo el cristianismo con sus promesas amorosas, y que hoy trasciende para beneficio de todos, lo mismo individual que colectivamente ${ }^{38}$.

Larrea ata así los cabos con las experiencias en Perú. No describe las experiencias como místicas, pero las menciones del cristianismo, así como del optimismo y el amor, son ecos de las descripciones más frecuentes de las experiencias místicas. Tan fuerte es la convicción de Larrea que dedica su vida y su obra a la voluntad objetiva. 
Pobrane z czasopisma Annales I - Philosophy and Sociology http://philosophia.annales.umcs.pl Data: 26/04/2023 16:59:48

\section{CONCLUSIÓN}

Tal y como la define James, la mística resulta paradójica como experiencia religiosa con relevancia para la filosofía. Aun así, James la acepta y la valida. Las experiencias místicas nacen de lo personal para entrar en unión con una realidad metafísica absoluta, pero no puede deducirse una verdad absoluta a partir de una experiencia personal precisamente porque es personal e inefable. No obstante, las experiencias religiosas poseen, para James, un valor especial porque son buenas para nosotros. En el pensamiento de Larrea, la mística viene a suponer una alternativa a la filosofía racional porque es tanto personal como universal. El uso de la razón, tal y como la emplean los existencialistas ${ }^{39}$, hace del allí un $a q u i^{40} \mathrm{y}$, como tal, imposibilita todo pensamiento metafísico. Tanto en Orbe como en Diario del Nuevo Mundo Larrea describe las experiencias que vive durante sus etapas en América Latina, donde la mística se presenta primero como experiencias que provocan angustia y vacío y, más tarde, como vehículo para la comprensión de la inutilidad de un yo individual frente a un proyecto con aspiraciones metafísicas. En este sentido Orbe y Diario vienen a ser los testimonios personales que dejan constancia del proceso por el que pasa el autor y la relevancia que tiene para su proyecto filosófico. El mismo Larrea no declara místicas las experiencias, pero destaca el contacto con una potencia absoluta, una voluntad objetiva y universal y, si en Orbe le producen angustia, en Diario del Nuevo Mundo se rinde frente al nuevo orden que le ha sido revelado. El Diario refleja claramente una comprensión del mundo que podríamos denominar "religiosa" porque el pensador ha arribado a ella mediante experiencias de rasgos místicos y claramente personales.

Orbe y Diario vienen a ser el fundamento metodológico de su filosofía posterior. Cuando empieza a escribir ensayos y libros filosóficos, especialmente a partir de los años 50, su estilo es más conformista y propio de una intelectualidad académica, ya que inserta su proyecto filosófico en un marco conceptual más objetivo; sin embargo, en sus inicios el pensamiento de Larrea es claramente una filosofía híbrida que se apoya en la poesía, la psicología, la religión y la mística, en búsqueda de una metodología que satisfaga sus inquietudes metafísicas. Define una filosofía "mística" porque solo esta le permite acceder la esfera del Espíritu no alcanzable para la razón. Este es su punto de partida metodológico.

39 En Razón de Ser, Larrea critica a los existencialistas el usar el hombre como medida de todas las cosas. El resultado es hacer del allí un aquí y, consecuentemente, imposibilitar acceder a la esfera del Espíritu a la que pertenece el Ser. Considera que tanto agnósticos como cristianos son existencialistas porque se refieren al Ser del sujeto vivo y no a un Ser absoluto. Véase idem, Razón de Ser, Madrid 1974, p. 28-31.

40 Ibídem. 


\section{BIBLIOGRAFÍA}

Abellán J.L., El exilio filosófico en América. Los transterrados de 1939, Madrid 1998.

Díaz de Guereñu J.M., Orbe de Juan Larrea, "Ínsula" 1990, Vol. 527.

Hodges M., The Claims for Mysticism in the Varieties of Religious Experience, "Journal of Speculative Philosophy" 2011, Vol. 25(4), DOI: https://doi.org/10.5325/jspecphil.25.4.0396.

James W., The Varieties of Religious Experience, New York 2015.

Larrea J., Diario del Nuevo Mundo, Madrid 2015.

Larrea J., Orbe, Barcelona 1990.

Larrea J., Razón de Ser, Madrid 1974.

Larrea J., Versión Celeste, Madrid 2003.

López González de Orduña H., Hacia una definición de Orbe de Juan Larrea, "Bulletin of Hispanic

Studies" 2001, Vol. 78(3), DOI: https://doi.org/10.1080/000749001300342070.

Martín Velasco J., El fenómeno místico, Madrid 2009.

Morelli G., Introducción, [en:] J. Larrea, Poesía y Revelación, Madrid 2009.

Nieto Nuño M., Introducción, [en:] J. Larrea, Versión Celeste, Madrid 2003.

Pittarello E., Juan Larrea: Desfiguraciones al uso, "Etudes Hispaniques” 1992, núm. 19.

Rorty R., Some Inconsistencies in James's Varieties, [en:] William James and a Science of Religions, New York 2004.

\section{SUMMARY}

The aim of the present study is to analyse the mystic traits of the experiences J. Larrea had in Peru and Mexico based on his testimonies in Orbe and Diario del Nuevo Mundo. It compares these experiences to W. James' definition of a mystic experience, and it analyses their evolution and fulfilment in order to explore the relationship between the personal and the absolute in Larrea's philosophical project. On this basis, the article argues that through mysticism, Larrea abandons the individual "I" as a thinking subject and that the foundation to a methodology of Larrea's metaphysical thinking is laid out in Orbe and Diario del Nuevo Mundo.

Keywords: Juan Larrea; mysticism; philosophy; the "New World"; diary

\section{STRESZCZENIE}

Celem niniejszego opracowania była analiza mistycznych cech doświadczeń J. Larrei w Peru i Meksyku, opisanych w Orbe i Diario del Nuevo Mundo. Zostały one porównane z definicją mistycznego doświadczenia W. Jamesa. Przeprowadzono analizę ich rozwoju i realizacji w celu zbadania relacji między tym, co osobiste i absolutne w filozoficznym projekcie Larrei. Na tej podstawie wskazano, że poprzez mistycyzm Larrea porzuca indywidualne ,ja” jako podmiot myślący oraz że podstawą metodologii jego metafizycznego myślenia są Orbe i Diario del Nuevo Mundo.

Slowa kluczowe: Juan Larrea; mistycyzm; filozofia; „Nowy Świat”; dziennik 
Pobrane z czasopisma Annales I - Philosophy and Sociology http://philosophia.annales.umcs.pl Data: 26/04/2023 16:59:48

\section{RESUMEN}

El objetivo del presente estudio es analizar los rasgos místicos de las experiencias vividas en Perú y México tal y como J. Larrea deja constancia de ellas en Orbe y Diario del Nuevo Mundo. Se comparan las experiencias de Larrea con la definición de la experiencia mística de W. James y se analizan la evolución y consumación de las mismas con el fin de demostrar la relación entre lo personal y lo absoluto en el pensamiento de Larrea. El estudio demuestra que mediante la mística, Larrea llega a abandonar el yo individual como sujeto de su pensamiento. De esta manera, Orbe y Diario del Nuevo Mundo vienen a ser la fundación de una metodología para la elaboración del pensamiento metafísico del autor.

Palabras claves: Juan Larrea; mística; filosofía; "Nuevo Mundo"; diario 